\title{
AVALIAÇÃO HISTOQUÍMICA QUANTITATIVA DO COLÁGENO NA FASCIA TRANSVERSALIS E NA BAINHA ANTERIOR DO MÚSCULO RETO ABDOMINAL EM DOENTES COM HÉRNIA INGUINAL
}

\author{
QUANTITATIVE HISTOCHEMICALANALYSIS OF COLAGEN IN FASCIA \\ TRANSVERSALIS AND ANTERIOR RECTUM SHEATH OF PATIENTS WITH \\ INGUINAL HERNIAS
}

\author{
Rogério de Oliveira Gonçalves, TCBC-RJ ${ }^{1}$ \\ Evandro de Moraes e Silva, TCBC-RJ ${ }^{2}$ \\ Tatiana Cunha Marques, ACBC-RJ ${ }^{3}$ \\ Gaspar de Jesus Lopes Filho, TCBC-SP ${ }^{4}$
}

\begin{abstract}
RESUMO: Objetivo: Avaliar a participação do colágeno na etiopatogenia das hérnias inguinais, através da análise quantitativa histoquímica do colágeno na bainha anterior do músculo reto abdominal e na fascia transversalis Método: Foram operados quarenta doentes do sexo masculino, na faixa etária entre 20 e 60 anos, portadores de hérnia inguinal tipo II e IIIA de Nyhus e realizadas autópsias em dez cadáveres frescos, na mesma faixa etária. Em ambos os grupos, amostras da bainha anterior do músculo reto abdominal e da fascia transversalis foram colhidas, coradas pela técnica histoquímica do picrocírius e submetidas a análise morfométrica quantitativa através de sistema computadorizado com a finalidade de identificar possíveis alterações quantitativas do colágeno, em cada um dos dois tipos de hérnias em comparação com indivíduos sem hérnias. Resultados: Encontramos maior concentração do colágeno na bainha anterior do músculo reto abdominal, em comparação a fascia transversalis em todos os grupos estudados, embora esta diferença tenha sido estatisticamente significante apenas no grupo controle. Não encontramos diferenças na concentração do colágeno, na bainha anterior do músculo reto abdominal e na fascia transversalis, entre os doentes com hérnias tipo II e tipo IIIA de Nyhus. Não encontramos diferenças na concentração do colágeno quando comparamos os grupos com hérnias com o grupo controle.Conclusão: Não encontramos diferenças na quantidade do colágeno na bainha anterior do músculo reto abdominal e na fascia transversalis entre os pacientes portadores de hérnia inguinal tipo II e IIIA de Nyhus em comparação com indivíduos sem hérnias.
\end{abstract}

Descritores: Hérnia Inguinal; Colágeno; Fáscia; Análise quantitativa.

\section{INTRODUÇÃO}

Estudos epidemiológicos desenvolvidos nos E.U.A, nas décadas de 80 e 90 , demostraram que a hérnia inguinal é uma doença freqüente, represen- tando cerca de $15 \%$ das operações em cirurgia geral, e constituindo um total de 700 mil procedimentos anuais ${ }^{1}$.

Fatores etiopatogênicos predisponentes, descritos como defeitos anátomo-funcionais, bem como

1. Mestre em Gastroenterologia Cirúrgica pela UNIFESP - EPM; Professor Assistente da Disciplina de Clínica Cirúrgica da Escola de Ciências Médicas de Volta Redonda - UNIFOA.

2. Mestre em Gastroenterologia Cirúrgica pela UNIFESP - EPM; Professor Assistente do Departamento de Morfologia e Anatomia da Escola de Ciências Médicas de Volta Redonda-UNIFOA.

3. Professora Assistente do Departamento de Morfologia e Anatomia da Escola de Ciências Médicas de Volta Redonda-UNIFOA.

4. Professor Livre Docente da Disciplina de Gastoenterologia Cirúrgica da Escola Paulista de Medicina - UNIFESP.

Trabalho realizado no Hospital São João Batista da Escola de Ciências Médicas de Volta Redonda e no Laboratório de Ginecologia Experimental da Universidade Federal de São Paulo. 
fatores desencadeantes,que são capazes de acarretar aumento da pressão intra abdominal, não explicam totalmente a etiologia desta afecção ${ }^{2}$.

A hérnia inguinal das crianças tem etiologia congênita e decorre da persistência do conduto peritônio vaginal. A hérnia inguinal do adulto, direta ou indireta,no entanto é de etiologia adquirida e decorre de alterações estruturais na fascia transversalis.

A fascia transversalis é formada por tecido conjuntivo denso,cuja principal célula é o fibroblasto que produz qrande quantidade de fibras colágenas e elásticas e também uma abundante matriz extracelular, rica em proteoglicanas e glicoproteínas, na qual ficam imersas essas fibras ${ }^{3,4}$.

Diversos trabalhos realizados a partir da década de 70, utilizando exames bioquímicos, histoquímicos e imunohistoquímicos procuraram associar a presença da hérnia inguinal adquirida com anormalidades no tecido conjuntivo e demonstram haver alterações quantitativas e qualitativas nos componentes deste tecido nos doentes portadores de hérnia inguinal ${ }^{4-6}$. Baseados em estudos observacionais que demostraram haver uma maior incidência de hérnias inguinais nos portadores de doenças do tecido conjuntivo $^{7-9}$, assim como nos portadores de doenças que sabidamente afetam o tecido conjuntivo ${ }^{10,11}$, objetivamos com esse trabalho realizar o estudo histoquímico comparativo de amostras da fascia transversalis e da bainha anterior do músculo reto abdominal, de adultos do sexo masculino, portadores de hérnias inguinais tipo II ou IIIA de Nyhus ${ }^{12,13}$, procurando identificar possíveis alterações quantitativas do colágeno em cada um dos dois tipos de hérnias, em comparação com indivíduos sem hérnia.

\section{MÉTODO}

Foram utilizados fragmentos da fascia transversalis e da bainha anterior do músculo reto abdominal, obtidos durante intervenções cirúrgicas para a correção de hérnias inguinais e durante autópsias realizadas no Hospital São João Batista da Escola de Ciências Médicas de Volta Redonda, no período de dezembro de 1997 a junho de 2000. Este estudo foi avaliado e aprovado pela comissão de ética Médica da Universidade Federal de São Paulo.

Foram constituídos três grupos:

Grupo I - Vinte doentes do sexo masculino, com idade entre vinte e sessenta anos, com hérnia inguinal tipo II de Nyhus e com risco cirúrgico ASA I ou ASA II.
Grupo II - Vinte doentes do sexo masculino, com idade entre vinte e sessenta anos, com hérnia inguinal tipo IIIA de Nyhus e com risco cirúrgico ASA I ou ASA II.

Grupo III - Dez cadáveres frescos, do sexo masculino, com idade entre vinte e sessenta anos, não portadores de hérnia inguinal.

Excluímos os doentes com doenças do sistema conjuntivo, idade menor que 18 anos e maior que 60 anos, o sexo feminino, os fumantes, os com risco cirúrgico ASA III ou IV, bem como doentes em que a hérnia inguinal não se enquadrava na classificação II e IIIA de Nyhus.

As amostras dos grupos I e II foram obtidas através da retirada de $1 \mathrm{~cm}^{2}$ da fascia transversalis da parede posterior do triângulo inguinal e também da bainha anterior do músculo reto abdominal do mesmo lado; as amostras do grupo III foram retiradas do mesmo local das dos grupos I e II, após a dissecção bilateral da região inguinal e a constatação de inexistência de saco hérniário. Retiradas as amostras, estas eram imediatamente lavadas em solução salina a $0,9 \%$ e fixadas em solução constituída de paraformaldeído a $10 \%$ (2,5ml), Phosfate Buffer Solution (PBS) concentrado $(5 \mathrm{ml})$ e água destilada $(2 \mathrm{ml})$, e armazenadas à temperatura de quatro graus Celsius durante duas horas. Após a fixação, a solução fixadora era desprezada com pipeta, e se adicionava $1 \mathrm{ml}$ de PBS concentrado e 9ml de água destilada, mantendo-se resfriado a quatro graus Celsius por mais $24 \mathrm{~h}$. As amostras obtidas eram incluídas em parafina e submetidas à cortes seriados transversais em micrótomo de modo a se obterem cortes na espessura de cinco micrômetros, que eram colocados sobre lâminas de vidro e postos a secar em estufas a $40^{\circ} \mathrm{C}$ de 12 a 24 horas. Todos os preparados histológicos, obtidos a partir dos cortes da bainha do músculo reto abdominal e da fascia transversalis, foram corados pelo método de picrosírius com a seguinte técnica:

- os cortes eram desparafinados em três banhos sucessivos de xilol (um minuto cada), hidratados em soluções de concentrações decrescentes de etanol (absoluto, 90\%, 70\% - um minuto cada) e água; eram então corados, com solução de picrosírirus durante 50 minutos e lavados em água destilada. A seguir, foi usada a solução de hematoxilina de Delafield (por quatro minutos), lavados em água corrente (cinco minutos) e água destilada (um minuto) e corados com eosina aquosa (um minuto) para, finalmente, serem desidratados em soluções crescentes de etanol (70\%, 
90\% e dois banhos de absoluto - um minuto cada), clarificados em três banhos de xilol (um minuto cada) e montados com lamínula, usando bálsamo do Canadá artificial. Esta técnica foi utilizada para revelar as fibras do sistema colágeno.

- as amostras coradas foram submetidas a análise morfométrica, no laboratório de Ginecologia Experimental da Disciplina de Ginecologia da Universidade Federal de São Paulo, através de sistema computadorizado com software de processamento e análise de imagem acoplado a microscópio com aumento de 400X - IMAGELAB (SOFTIUM INFORMÁTICA LTDA). Para a quantificação das áreas representativas do colágeno, uma vez que as imagens eram sistematicamente uniformes, foram digitalizados apenas três campos por lâminas e cada

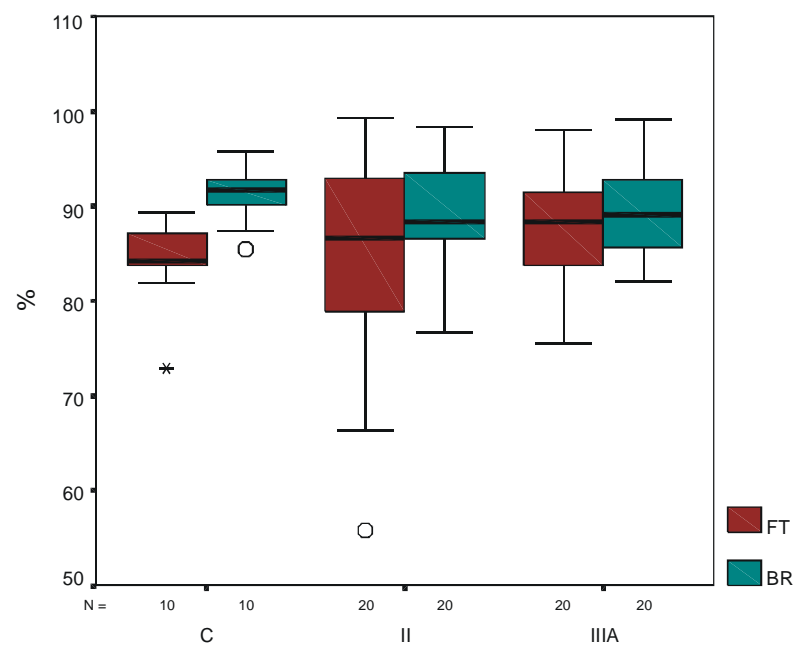

Figura 1 - Valores da concentração do colágeno na fascia transversalis e na bainha anterior do músculo reto do abdome nos grupos: controle (C), hérnia tipo II de NYHUS (II) e hérnia tipo IIIA de NYHUS (IIIA)

* Valores extremos, fora da média.

Foram aplicados os teste de Wilcoxon para análise intra-grupos e o teste de Mann-Whitney para análise inter-grupos e o nível de significância adotado foi de 0,05 ou $5 \%$, assinalando-se com asterisco (*) os valores significantes.

\section{RESULTADOS}

Uma maior concentração de colágeno foi encontrado na bainha anterior do músculo reto abdominal quando comparado com a fascia transversalis campo digitalizado correspondeu à área de 395 micras de largura por 300 micras de altura na imagem real. Antes do processo de quantificação propriamente dito, todas as imagens foram digitalizadas padronizandose a objetiva, a intensidade da luz do microscópio e a altura do condensador.

- as áreas de colágeno foram identificadas na imagem, utilizando-se a distribuição de cor como parâmetro discriminante. $\mathrm{O}$ intervalo de cor foi definido de forma empírica através de tentativa e erro entre uma faixa de cor que foi sendo ajustada até separar as áreas representativas do colágeno na imagem. Na etapa seguinte, calculou-se a área ocupada pelo colágeno em cada um dos campos, sendo os resultados expressos em porcentagem.

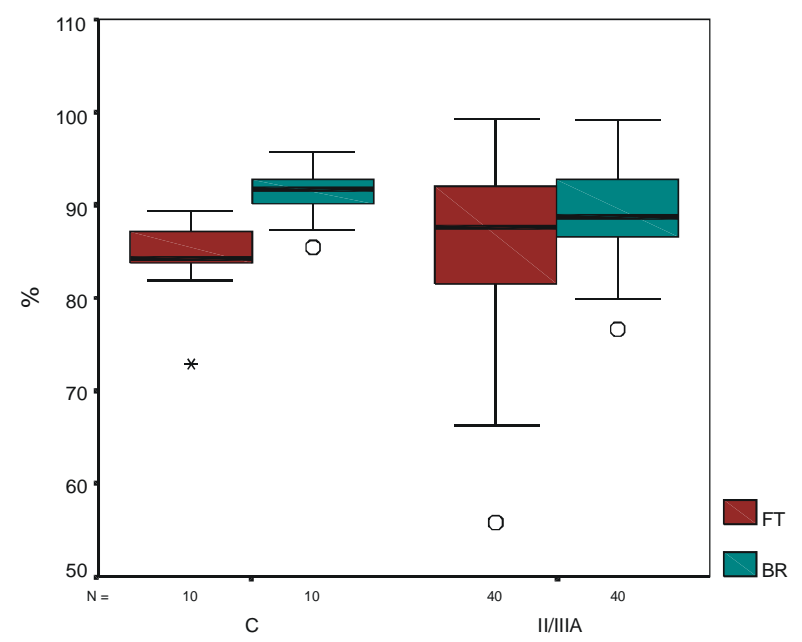

Figura 2 - Concentação do colágeno na fascia transversalis e na bainha anterior do músculo reto do abdome nos grupos controle (C) e com hérnias (II / IIIA)

* Valores extremos, fora da média.

em todos os grupos estudados, embora esta diferença tenha sido estatisticamente significante apenas no grupo controle (Figura 1).

Quando comparamos as concentracões do colágeno da bainha anterior do músculo reto abdominal e da fascia transversalis entre os grupos I e II não houve diferença estatisticamente significante (Tabela 1), o que nos permitiu agrupar os valores de concentração do colágeno, da bainha anterior do músculo reto abdominal e da fascia transversalis, nos grupos com hérnias (I e II) e os comparamos com os 
valores da concentração do colágeno da bainha anterior do músculo reto abdominal e da fascia transversalis com grupo controle (III), e não encontramos diferenças estatisticamente significantes (Figura 2).

\section{DISCUSSÃO}

Baseados em estudos que demonstraram aumento da atividade elastolítica sérica de fumantes com hérnia inguinal, em comparação com os não fumantes sem hérnia ${ }^{14,15}$ e em estudos que demonstraram diminuição da hidroxilação da prolina, com conseqüente prejuízo na síntese do colágeno e na cicatrização de feridas nos doentes com hábito de fumar cigarros ${ }^{16}$, optamos pela exclusão deste grupo em nosso estudo, e também limitamos a faixa etária dos nossos doentes entre 20 e 60 anos, com intuito de excluir as alterações do tecido conjuntivo próprias do envelhecimento ${ }^{6}{ }^{17}$.

$\mathrm{O}$ diabetes melito induz a várias alterações no metabolismo das macromoléculas presentes na matriz extracelular. Entre essas, ocorre a diminuição na síntese do colágeno, determinando alterações na proporção entre o colágeno tipo I e o colágeno tipo III, presentes nos tendões e fáscias ${ }^{18}$, o que também foi fator determinante na exclusão destes doentes.

A fascia transversalis é constituída por tecido conjuntivo, onde a principal célula observada é o fibroblasto. Os mastócitos são raros e os linfócitos, o plasmócitos e o neutrófilos são observados sobretudo em processos inflamatórios. Estas células estão mergulhadas em uma proporção relativamente grande de matriz extracelular, constituída por elementos fibrosos, que são as fibras colágenas e elásticas, e também por macromoléculas, as proteoglicanas e as

Tabela 1 - Valores da concentração do colágeno nos grupos com hérnia.

\begin{tabular}{cccc}
\hline Grupo/Amostra & NYHUS II & NYHUS IIIA & Valor de p \\
\hline Bainha do Reto & 88,3 & 89,05 & 0,892 \\
mediana (min-máx) & $(76,6-98,4)$ & $(82,0-99,1)$ & \\
& & & \\
Fascia Transversalis & 86,7 & 88,38 & 0,598 \\
mediana (min-máx) & $(55,8-99,3)$ & $(75,5-98,1)$ & \\
\hline
\end{tabular}

Teste de Mann-Whitney

glicoproteínas. A organização e a interação desses constituintes da matriz é que determinam a função estrutural e a estabilização física da fascia transversalis $^{19-21}$. O colágeno é o principal constituinte histológico fibroso desta fascia, que é constituída de fibras grossas dispostas em um mesmo plano e em diferentes direções, o que fornece a força tênsil e resistência a esta estrutura ${ }^{14}$.

As alterações morfológicas na fascia transversalis parecem ser condições predisponentes para o aparecimento de hérnias, portanto buscar alterações quantitativas do colágeno na fascia transversalis de portadores de hérnias diretas e indiretas, bem como compará-las com a presença de alterações quantitativas do colágeno na bainha anterior do músculo reto do abdome, na tentativa de evidenciar se estas alterações são locais ou sistêmicas, nos pareceu uma maneira de compreender a etiopatogenia das hérnias inguinais. $\mathrm{O}$ colágeno representa um dos constituintes fibrosos da matriz extracelular, também constituída por substância amorfa, composta por proteoglicanas e glicoproteínas, podendo a etiologia das hérnias inguinais estar relacionada com alterações quantitativas ou morfológicas de uma ou mais dessas substâncias.

Avaliação das fibras colágenas através da dosagem bioquímica da hidroxiprolina, demonstraram diminuição desta nos pacientes com hérnia inguinal ${ }^{22}$. Análises ultra-estruturais evidenciam mudanças qualitativas e quantitativas nas microfibrilas do colágeno na região da hérnia inguinal ${ }^{23}$. Esses resultados podem ser comparados com os encontrados em pacientes portadores de desordens do sistema conjuntivo localizadas em outros órgãos ${ }^{9}$ 
Em nosso estudo, realizamos a análise de um dos constituintes fibrilar da matriz extracelular, através de método histoquímico, utilizando a coloração de Picrosírius que seleciona exclusivamente as fibras colágenas ${ }^{24}$ sendo estas quantificadas através de um sistema de processamento de imagem por computador, IMAGELAB ${ }^{25}$

Vários trabalhos não classificam o tipo de hérnia inguinal avaliada, provavelmente utilizam biópsias de fascia transversalis que poderiam apresentar alterações decorrentes da presença de sacos herniários inguino-escrotais volumosos, o que impossibilitaria determinar se estas alterações ultra-estruturais são consequiêntes a presença da hérnia ou a causa desta.

Nesse trabalho, selecionamos pacientes com hérnias diretas e indiretas, em que não houvesse destruição total da parede posterior do canal inguinal. Para tanto, utilizamos a classificação de Nyhus para hérnias inguinais e selecionamos apenas as hérnias tipo II e tipo IIIA dessa classificação ${ }^{12,13}$.

Os grupos controles, utilizados pelos traba$\operatorname{lhos}^{2,3,5}$, analisaram amostras da bainha anterior do músculo reto abdominal obtidas com incisões infraumbilicais medianas para o tratamento de afecções que também apresentam desordens do sistema conjuntivo, como os portadores de aneurismas de aorta abdominal $^{3}$, tornando inadequada tal comparação. Em nosso experimento, o grupo controle foi constituído por cadáveres não portadores de hérnia inguinal, o que possibilitou que as amostras da bainha anterior do músculo reto abdominal e da fascia transversalis fossem colhidas diretamente da região inguinal.

Em discordância com os trabalhos anteriores, que realizaram análises ultra-estruturais e bioquímicas da fascia transversalis de doentes com hérnias inguinais ${ }^{2}$, e analisaram características biomecânicas dessa estrutura ${ }^{4}$, não evidenciamos diferenças significantes entre os doentes com hérnias inguinais, quando comparados com doentes sem hérnias inguinais.
As dificuldades na análise desses trabalhos estão, inicialmente na seleção do tipo de hérnias, pois foram utilizados indiscriminadamente pacientes com hérnias tipo II, IIIA, IIIB e IIIC e na utilização de doentes de ambos os sexos, uma vez que as mulheres podem apresentar alterações do sistema conjuntivo relacionadas com distúrbios hormonais determinados pela gravidez ${ }^{26}$. Além disso, a utilização de idosos também pode interferir nos resultados desses trabalhos, uma vez que existem alterações das fibras colágenas e elásticas acima dos 60 anos.

Por outro lado, trabalhos com culturas de fibroblastos in vitro, mostram alterações quantitativas decrescentes dos fibroblastos, nos portadores de hérnia inguinal indireta e hérnia inguinal direta, quando comparados a um grupo controle sem hérnia inguinal. Estas alterações seriam responsáveis pelo menor conteúdo de colágeno nos doentes com hérni$\operatorname{as}^{27,28}$. Na verdade, estas alterações também poderiam ser responsáveis pela diminuição de outros constituintes fibrilares, tais como as fibras elásticas e também os constituintes protéicos da matriz extracelular, como as proteoglicanas.

Em nosso trabalho, a análise morfométrica computadorizada do colágeno na bainha anterior do músculo reto abdominal e na fascia transversalis em comparação com a análise do grupo controle, não mostrou alterações estatisticamente significantes. No entanto, avaliamos as fibras colágenas de uma forma global e não quantificamos separadamente os colágenos tipo I e tipo III, que, estando em concentrações alteradas não interfeririam na concentração total do colágeno e sim nas concentrações relativas do mesmo ${ }^{7}$.

Outros estudos, utilizando métodos bioquímicos, imunohistoquímico e ultra-estruturais deveriam ser realizados, não só para avaliação das fibras colágenas, mas também de outros constituintes da matriz extracelular como as fibras elásticas, as glicoproteinas e as proteoglicanas, os quais podem estar envolvidos na etiopatogenia das hérnias inguinais no adulto. 


\begin{abstract}
Background: To evaluate the role of colagen in etiopathogeny of inguinal hernias through quantitative histochemical analysis of the abdominal rectum sheaths and fascia transversalis. Methods: Forty male patients with Nyhus type II and III inguinal hernias, were operated, age ranged from 20 to 60 years, and ten control subjects with the same age were autopsied. Samples were collected from rectum sheaths and fascia transversalis from each group, and collored by the histochemical technique Picrocirius and morphometric analysis, which was carried out by using the image representation technique. These studies focused mainly on identify the possible quantitative changes in collagen in each of the two types of hernias compared to individuals without hernias. Results: We found an increased collagen concentration in rectum sheath when compared to fascia transversalis in all groups studied. These diferences, however, was only estatistically significant in control group. We found no difference in collagen concentration in rectum sheaths and fascia transversalis from pacients with Nyhus type II or III hernias. No diference in collagen concentration was found in hernias'group compared to control group. Conclusion: There was no statistically significant difference between the amount of collagen of abdominal rectum sheaths and of the fascia transversalis among patients with Nyhus type II and IIIa inguinal hernias and the amounts found in individuals without hernias.
\end{abstract}

Key Words: Inguinal hernia; Collagen; Fascia; Quantitative analysis.

\section{REFERÊNCIAS}

1. Rutkow IM, Robbins AW - Demographic, classificatory, and socioeconomic aspects of hernia repair in the United States. Surg Clin North Am, 1993, 73(3): 413426.

2. Bellón JM, Buján J, Honduvilla NG, et al. - Study of biochemical substrate and role of metalloproteinases in fascia transversalis from hernial processes. Eur $\mathbf{J}$ Clin Invest, 1997, 27(6): 510-516.

3. Wagh PV, Leverich AP, Sun CN, et al. - Direct inguinal herniation in men: a disease of collagen. J Surg Res, 1974, 17(6): 425-433.

4. Pans A, Pierard GE, Albert A, et al. - Adult groin hernias: new insight into their biomechanical characteristics. Eur J Clin Invest, 1997, 27(10): 863868.

5. Read RC - Attenuation of the rectus sheath in inguinal herniation. Am J Surg, 1970, 120(5): 610-614.

6. Rodrigues Jr AJ, de Tolosa EM, de Carvalho CA Electron microscopic study on the elastic and elastic related fibres in the human fascia transversalis at different ages. Gegenbaurs Morphol Jahrb, 1990 ,136(6): 645-652.

7. Friedman DW, Boyd C D, Norton P, et al. - Increases in type III collagen gene expression and protein synthesis in patients with inguinal hernias. Ann Surg, 1993, 218(6): 754-760.

8. Udén A, Lindhagen T - Inguinal hernia in patients with congenital dislocation of the hip. A sign of general connective tissue disorder. Acta Orthop Scand, 1988, 59(6): 667-668.
9. Wesley JR, Mahour H, Woolley MM - Multiple surgical problems in two patients with Ehlers - Danlos syndrome. Surgery, 1980, 87(3): 319-324.

10. Colin JF, Elliot P, Ellis H - The effect of uraemia upon wound healing: an experimental study. Br J Surg, 1979, 66(11): 793-797.

11. Chan MK., Baillod RA, Tanner A, et al. - Abdominal hernias in patients receiving continuous ambulatory peritoneal dialysis. Br Med J, 1981, 283(6295): 826.

12. Nyhus LM - Individualization of hernia repair: a new era. Surgery, 1993, 114(1): 1-2.

13. Nyhus LM, Klein MS, Rogers FB - Inguinal Hernia. Curr Probl Surg,1991, 28(6): 401-450.

14. Berliner SD - Adult inguinal hernia: pathophysiology and repair. Surg Annu, 1983,15: 307-329.

15. Jorgensen LN, Kallehave F, Christensen E, et al. - Less collagen production in smokers. Surgery, 1998, 123(4): 450-455.

16. Cannon DJ, Read RC. Metastatic emphysema: a mechanism for acquiring inguinal herniation. Ann Surg, 1981, 194(3): 270-278.

17. Tsuji T, Hamada T - Age-related changes in human dermal elastic fibres. Br J Dermatol, 1981, 105(1): 57-63.

18. Sternberg M, Cohen-Forterre L, Peyroux J - Connective tissue in diabetes mellitus: biochemical alterations of the intercellular matrix with special reference to proteoglycans, collagens and basement membranes. Diabete Metab, 1985, 11(1): 27-50.

19. Nimni ME - Collagen: structure, function, and metabolism in normal and fibrotic tissues. Semin Arthritis Rheum, 1983 13(1): 1-86. 
20. Olsen BR. New insights into the function of collagens from genetic analysis. Curr Opin Cell Biol, 1995, 7(5): 720-727.

21. Franco TR - Estudo da distribuição tridimensional das fibras conjuntivas na pele da parede abdominal e sua importância nas incisões cirúrgicas. Dissertação (Doutorado em Cirurgia Plástica). Rio de Janeiro. Universidade Federal, 1995, 71p.

22. Wagh PV, Read RC - Collagen deficiency in rectus sheath of patients with inguinal herniation. Proc Soc Exp Biol Med, 1971, 137(2): 382-384.

23. Nikolov VP, Beltschev B - Einige ultrastrukturelle Besonderheiten der Fascia transversalis bei direkten Leistenhernien seniler Männer. Anat Anz, 1990, 170 (3-4): 265-272.

24. Montes GS, Junqueira LCU - The use of the Picrosiriuspolarization method for the study of the biopathology of collagen. Mem Inst Oswaldo Cruz, 1991, 86(Supl3): 1-11.

25. Novelli MD, Barreto E, Matos D et al. Aplicação de processamento de imagens por computador na quantificação das variáveis histopatológicas da reparação tecidual de anastomose colocólicas em cães. Rev Assoc Med Bras, 1997,43(4): 277-282.
26. Junqueira LC, Zugaib M,Montes GS, et al. Morphologic and histochemical evidence for the occurrence of collagenolysis and for the role of neutrophilic polymorphonuclear leukocytes during cervical dilation. Am J Obstet Gynecol, 1980, 138(3): 273-281.

27. Ajabnoor MA, Mokhtar AM, Rafee AA, et al. Defective collagen metabolism in Saudi patients with hernia. Ann Clin Biochem, 1992, 29( Pt 4): 430436.

28. Wagh PV, Read RC - Defective collagen synthesis in inguinal herniation. Am J Surg, 1972, 124(6): 819 822.

Endereço para Correspondência: Rogério de Oliveira Gonçalves

Rua das Nogueiras, 81;

Condomínio Village Sul ,Jardim Belvedere,

Volta Redonda(RJ) CEP: 27258-150

e-mail:r.gov@uol.com.br 